\title{
Interpersonal Communication: An Analysis from a Point of In-house Communications
}

\section{Seiji Nomura}

GAM Japan Limited, Tokyo, Japan

Objectives: In-house communication consists of managerial communication (from a manager to his or her team members) and organizational communication (overall communications within a team, office, or company). This study aims to explain the particularity of office communications from the perspective of in-house communications and focusing on a case of a small office in Japan. Methods: The case is reviewed and analyzed in terms of communication issues: How the receiver interprets meanings of messages and how the sender understands implications from the receiver. The reasons and backgrounds of communication problems are explained.

Results: Since e-mails as written communication and as a tool used instead of oral communication are widely used at present, the e-mail recipient will need to understand what the sender wants to say by interpreting implications between one word and another or between one sentence and another.

Conclusions: Communication culture in Japanese society has been regarded as a high-context culture in which non-verbal aspects are more important than verbal ones. Japanese people can thus easily assume and understand what other people want to say even though they use few words. Since e-mails are now often used instead of oral communication, the e-mail recipient will need to understand what the sender wants to say by interpreting implications between one word and another or between one sentence and another. In order to do this, it is important to communicate with each other in person on a regular basis.

Key Words: Office Communication, Managerial Communication, Organizational Communication, High/Low Context Culture, Verbal/Non-verbal Communication

\section{Introduction}

A company's management or senior persons are responsible for building and maintaining a safe and sound work environment

Received: Jul 1, 2018 Revised: Jul 16, 2018 Accepted: Jul 20, 2018 Corresponding author: Seiji Nomura

GAM Japan Limited, 3-5-17-409, Shimouma, Setagaya-ku, Tokyo 154-0002, Japan

Tel: +81-3-5219-8803, E-mail: seijinomura@nifty.com

This is an Open Access article distributed under the terms of the Creative Commons Attribution Non-Commercial License (http://creativecommons.org/licenses/ by-nc/4.0/) which permits unrestricted non-commercial use, distribution, and reproduction in any medium, provided the original work is properly cited.

Copyright $\odot 2018$ Korean Association for Business Communication. to which the employees can devote themselves to their assigned work. We sometimes tend to leave small issues unresolved if we believe that these issues can be easily resolved in the future. As issues that may be considered small may seem large to others, however, these issues can sometimes cause unexpected problems.

It is understood that the message exchanged between the sender and receiver in communications consists of both a verbal and non-verbal message. In this study, the author will explain the particularity of office communications from the perspective of in-house communications. Then the author will analyze a communication issue in the office focusing on how the receiver 
interprets meanings of certain message and how the sender understands implications from the receiver and then explore reasons the communication problem occurred.

In the conclusion of the study, the author will suggest that, because each person has a different viewpoint on the same issue even in a small office, it is important for the sender to understand how the receiver gives meaning to a particular message and predict possible implications prior to sending the message. It is also important for the receiver to understand what implications the sender suggested in the message and forecast a possible implication prior to sending the response. The author will also suggest how the management and senior persons of the company can build smooth communication in their office to avoid miscommunication issues.

\section{Methods}

\section{Case Background}

An incident occurred in a small office: A certain employee (Person A) was in good health but started clearing their throat during work, and an employee close by (Person B) complained about this, ultimately bringing this issue to the attention of office superiors.

More specifically, Person A joined this company (Company $\mathrm{X}$ ) as a team leader. After joining Company X, Person A started clearing their throat in the office. Seeing this, Person B placed deodorizers around the office and several air cleaning machines around their desk. At this stage, Person B did not say anything to Person A or anyone else in the office and only took the actions previously mentioned. Then, after several months, Person $\mathrm{B}$ raised a complaint to a local HR person (Person C) by e-mail. Person $\mathrm{C}$ reported this concern to a local supervisor of Company $\mathrm{X}$ (Person D) and asked Person $\mathrm{D}$ to change the seating arrangements to minimize the possibility of Person B being infected with something. Person D, however, did not respond to this e-mail in a timely manner, which caused this issue to be brought to higher-level senior members of the company (Figure 1).

The particularities in this case are that there were only non-verbal communications - i.e., physical actions - taken by Person B when communicating with Person A and between Persons $B$ and D. In addition, communications between Persons $B$ and $C$ and between Persons $C$ and $D$ were performed by e-mail. The main purpose of this study is to analyze this case by taking it as an in-house communication issue.

\section{In-house Communication}

In-house communication consists of managerial communication and organizational communication (Norisada, 1996). Managerial communication is communication from a manager to his or her team members. Managers communicate in order to convey instructions to their team members and maintain a sense of hierarchy within the organization.

In general, a manager obtains information from the following five basic media (Mintzberg, 1973): (1) Documented communication, (2) Oral communication over the telephone, (3) Faceto-face communication at informal meetings, (4) Face-to-face communication at formal meetings, and (5) Visual communication.

Regarding (1), documented communication, the main tool at present is e-mail. E-mail is useful and convenient in respect of swiftness and confidentiality. In terms of swiftness, we can immediately send messages to other people at any time and from anywhere. In addition, in respect to confidentiality, it is a convenient way to convey a confidential message to a specific person. Regarding (2), oral communication over the telephone, this is a useful communication method as the message sender and receiver can talk with each other while concurrently confirming the reactions of the other person. Regarding (3), faceto-face communication at informal meetings, this includes conversations with team members inside or outside the office. This is an important opportunity for managers to get informal

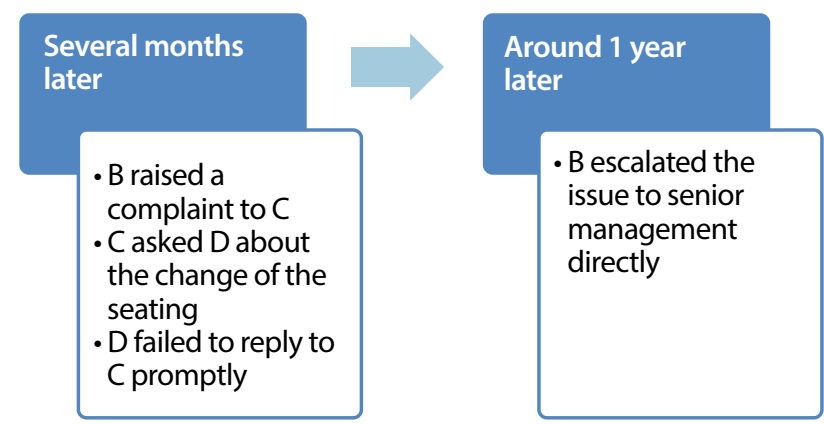

Around 1 year

B escalated the issue to senior management directly

Figure 1. The case in time manner.
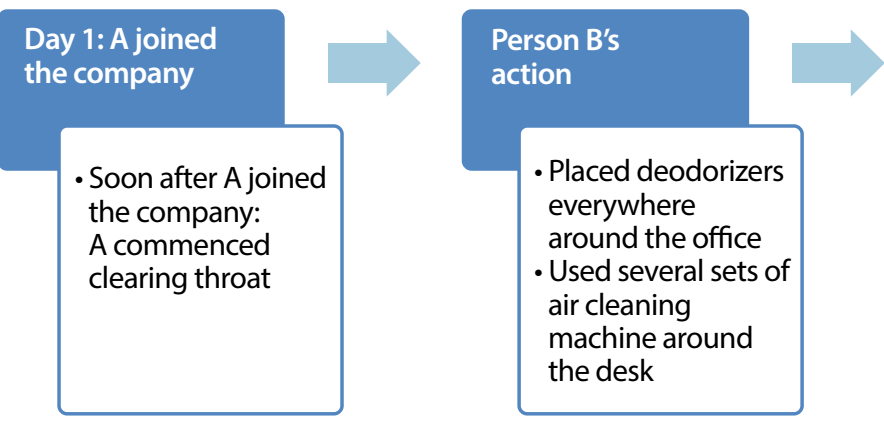
information. Regarding (4), face-to-face communication at formal meetings, this is an opportunity to get formal in-house information from team members as the conversations at formal meetings can be regarded as formal information. Regarding, (5) visual communication, this includes visible information such as gestures, attitudes, facial expressions, etc. In order to understand visual information correctly, however, it requires background knowledge, i.e. the sender and receiver often communicate with each other and each person is in a position to easily estimate what the other person wants to say.

\section{Managerial Communication}

As mentioned above, managerial communication is intended to convey a manager's instructions to the team members and to maintain a sense of hierarchy within the organization. A manager's responsibility consists of three roles: (1) Figurehead, (2) Liaison, and (3) Leader (Mintzberg, 1973). And, a manager's informational roles as information processing system are (1) Spokesperson to outsiders, (2) Disseminator to team members, (3) Monitor to gather external information through the liaison role from contacts, informers, peers and experts, and internal information through the leader role from team members, and (4) Strategy-maker to gather information to make models and plans and information to identify problems and opportunities (Mintzberg, 1973). In addition, the manager will do the work as a specialist when he or she performs professional work. In addition to the above, managers will act as a generalist when they manage their team members as a leader. In other words, in respect to managerial communication, a manager's roles are generalist in that they involve conveying, administering, and intermediating information necessary for the team and handling problems within the team. In this respect, a manager's ability to scan information is important.

\section{Organizational Communication}

Organizational communication includes the overall communications within a team, office, or company including communication from team members to their manager. According to the classical approach (Miller, 2015), there are a number of possible directions in which communication can flow, e.g., flowing vertically up and down the organization chart or horizontally among people of the same level. In organizational communication, the main channel of communication at present is e-mail. As organizational communication will tend to be top-down, the style of written and task-related communication will be highly formal.

\section{Results}

\section{Managerial Communication Approach}

For Person A and D, as mentioned above, the manager's informational role with respect to managerial communication is a generalist one. Thus, Person A and D need to gather internal information within their team (or local organization) through their leader's roles. However, for Person A and D, as there was no direct verbal communication between them and person $B$, they had to interpret Person B's message based solely on their physical actions (i.e., placing deodorizers around the office and using several air cleaning machines around their desk). Furthermore, since communications between Persons $\mathrm{B}$ and $\mathrm{C}$ and between Persons $\mathrm{C}$ and $\mathrm{D}$ were performed only by e-mail, Person $\mathrm{D}$ could not understand the strength of Person B's message and their emotional reaction to this matter because the e-mail message did not convey any emotion.

In this respect, the selection of media suitable for an occasion is essential especially when we talk about non-routine issues. Each medium for communication has a different nature, and it is crucial to select an appropriate medium relevant to the occasion at hand (Lengel \& Daft, 1988). According to Figure 2, the highest medium in terms of richness is physical presence (faceto-face discussions), and the lowest one is impersonal static media, such as fliers. When we perform a face-to-face conversation with others, we can realize emotional cues and the strength of the emotion of the other person by noticing facial expressions and the tone of the conversation. For e-mails, if we use them as an interactive medium, they could be regarded as a rather rich medium (interactive media in Figure 2). However, if we use e-mail only as a unilateral communication tool, it could be regarded as a less rich medium (personal static media in Figure 2).

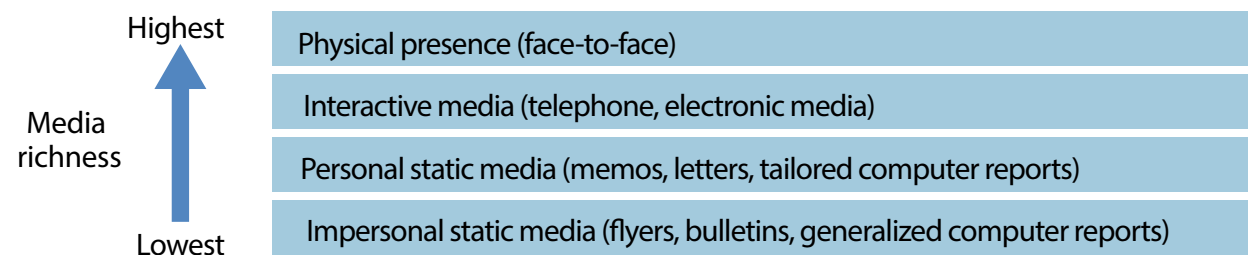

Figure 2. Hierarchy of media richness (Lengel \& Daft, 1988, p. 226). 
Thus, it is important for managers to select the richest medium possible when they discuss non-routine issues with their team members because they have to see physical reactions in order to interpret messages from others correctly.

Person $\mathrm{A}$ and $\mathrm{D}$ failed to gather such internal information within their team, and both Person A and D were not able to correctly interpret the messages from Person B or take the appropriate actions.

\section{Organizational Communication Approach}

In organizational communication, communication can flow vertically up and down the organizational chart as well as horizontally among employees at the same level. From this perspective, Persons A and D failed to realize the issue correctly and were not able to convey the right message to Person $\mathrm{B}$. On the other hand, Person B's style of communication was visual or non-verbal only to Person A and D. Therefore, if Persons A and $D$ properly collected internal information within their team (or local organization) through their leader's role, they could have correctly understood the visual or non-verbal message from Person B. However, as horizontal communication at the same level was not apparently performed by Person B, if Persons A and $\mathrm{D}$ collected internal information within their team, it might have been difficult for them to take the right action.

Regarding the communication from Person B to Person C and from Person $C$ to Person D, these messages were conveyed only by e-mail. This fact suggests that the e-mail recipientsi.e., Persons $\mathrm{C}$ and $\mathrm{D}$-would have to understand the message in the e-mail interpreting the implications between one word and another and one sentence and another. Such an interpretation would be difficult unless there were frequent face-to-face communications among them.

\section{Discussion}

According to Figure 3, Japanese society has been recognized as a high-context culture. However, according to research done at the end of 2011 by the Ministry of Internal Affairs and Communications of Japan (Ministry of Internal Affairs and Communications, 2012), the Internet penetration rate in Japan among people between 13 and 60 years was more than 90\%, and 70.1\% of these Internet users replied that their primary purpose of Internet was to use e-mail. The author thus thinks that cultural aspects of Japanese society are changing rapidly because e-mail (including SMS) as a communication tool used instead of oral communication has been spreading while opportunities to others in person or over the telephone are decreasing (Figure 3). The author intends to continue this research.
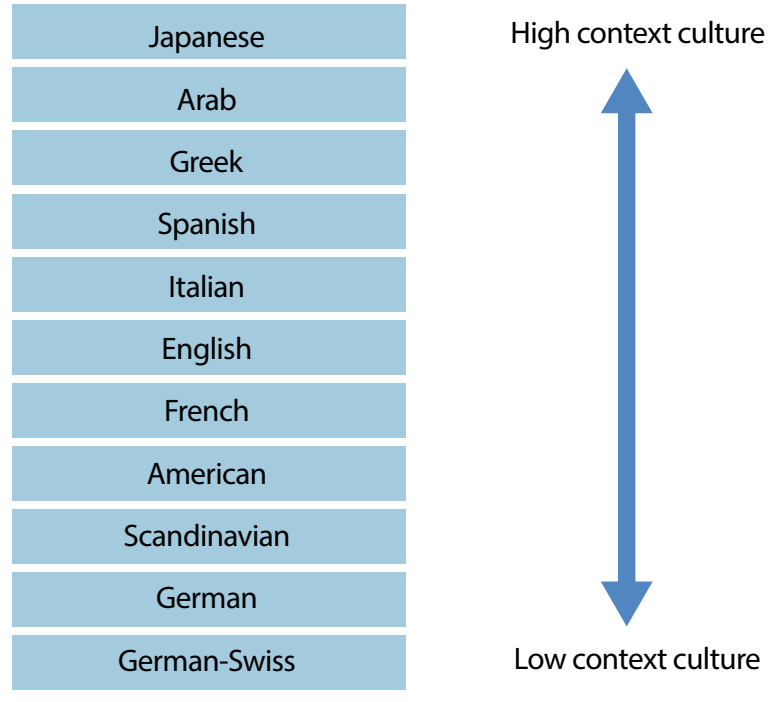

Figure 3. High and low context cultures (Samovar \& Porter, 1997, p. 24; Sueda \& Fukuda, 2011, p. 132).

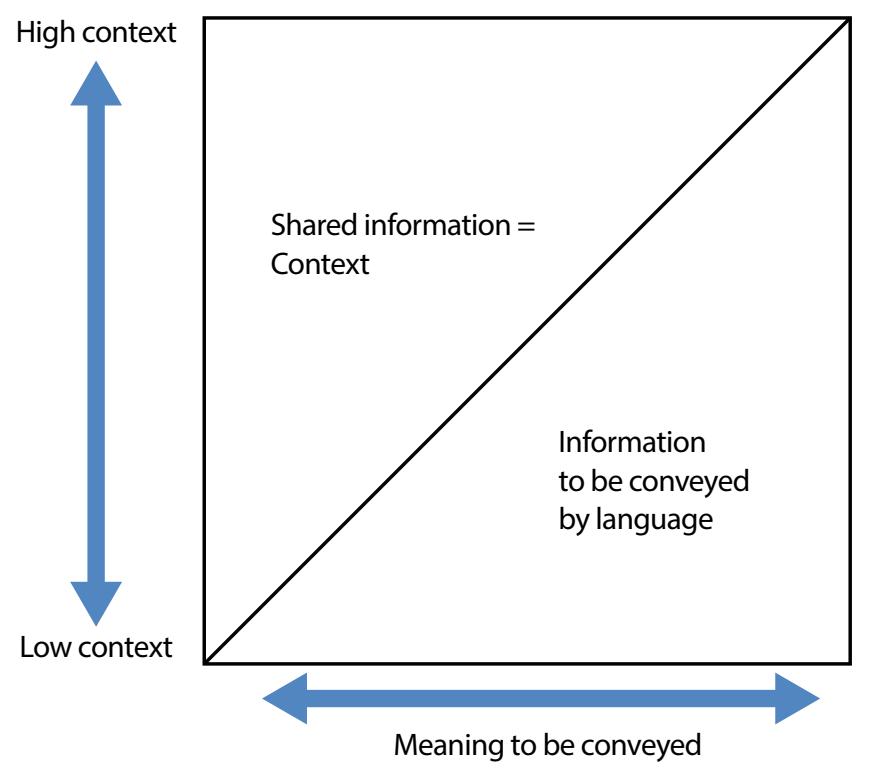

Figure 4. Combination of shared information and meaning to be conveyed (Sueda \& Fukuda, 2011, p. 131).

Communication culture in Japan has been regarded as a high-context culture in which non-verbal aspects are more important than verbal ones (Figure 4). Japanese people can thus easily assume what other people want to say based on a few words. This kind of scenario is feasible, however, only on the assumption that face-to-face discussions are proceeding well. When a message is sent by e-mail alone, the receiving person will need to interpret and understand what the sender wants to say between one word another and one sentence and another. However, interpreting the sender's message correctly by e-mail 
alone is too difficult for the receiver unless face-to-face communication is performed effectively, especially if the issue is non-routine, as e-mail filters out emotional aspects.

\section{Conclusion}

In this paper, the author reviewed and analyzed a certain case that was triggered by a communication problem in a certain office in order to identify causes of the problem and prevent further miscommunication in the future.

Through this study, the author reached the conclusion that communication culture in Japanese society has been regarded as a high-context culture in which non-verbal aspects are more important than verbal ones, which allows Japanese people to assume what the other person wants to say based upon only a few words. However, as e-mails are widely used instead of oral communication, the traditional perspective, which is based on a high-context culture, may no longer apply to communication in Japanese society. In other words, the Japanese people must see and review communication issues from not only a high-context cultural perspective but also a low-context cultural one. Thus, in order to realize problem-free communication in the office, it is important to frequently communicate with each other in face- to-face interactions.

\section{References}

Lengel, R. H., \& Daft, R. L. (1988). The selection of communication media as an executive skill. The Academy of Management Perspectives, 2(3), 225-232.

Mintzberg, H. (1973). The nature of managerial work. New York, NY: Harper Collins Publishers Inc.

Miller, K. (2015). Organizational communication: Approaches and processes (7th ed.). Stamford, CT: Cengage Learning.

Ministry of Internal Affairs and Communications. (2012). Results of the telecommunications usage trend survey 2011. Retrieved from http://www.soumu.go.jp/johotsusintokei/statistics/ data/120530_1.pdf

Norisada, T. (1996). Systematization of business communication studies by integrating individual research. Journal of Business Administration of Kwansei Gakuin University, 43(2-4), 61-83.

Samovar, L. A., \& Porter, R. E. (1997). Intercultural communication: A reader (8th ed.). Belmont, CA: Wadsworth.

Sueda, K., \& Fukuda, H. (2011). Communication studies: Its outlook and perspectives. Tokyo, Japan: Shohakusha. 